Perinatology pISSN 2508-4887 • elSSN 2508-4895

\section{Original article}

Perinatology Vol. 30, No. 3, September, 2019

https://doi.org/10.14734/PN.2019.30.3.160

\title{
Levothyroxine Sodium Administration and Late Circulatory Collapse in Premature Infants with Thyroid Dysfunction
}

\begin{abstract}
Hyun-Jeong Do, MD', Jae Young Cho, $\mathrm{MD}^{2}$, Jung Sook Yeom, MD, $\mathrm{PhD}^{2,3}$, Ji Sook Park, MD, PhD 2,3 , Ji-Hyun Seo, MD, PhD ${ }^{2,3}$, Jae Young Lim, MD, PhD ${ }^{2,3}$, Chan-Hoo Park, MD, PhD ${ }^{1,2}$, Hyang-Ok Woo, MD, PhD ${ }^{2,3}$, Hee-Shang Youn, MD, $\mathrm{PhD}^{2,3}$

'Department of Pediatrics, Gyeongsang National University Changwon Hospital, Changwon; 'Department of Pediatrics, College of Medicine, Gyeongsang National University, Jinju; Institute of Health Science, Gyeongsang National University Hospital, Jinju, Korea
\end{abstract}

Received: 28 April 2019

Revised: 23 June 2019

Accepted: 27 August 2019

Correspondence to

Ji Sook Park, MD, PhD

Department of Pediatrics, College of Medicine, Gyeongsang National University, 15 Jinju-daero 816beongil, Jinju 52727, Korea

Tel: +82-55-750-8156

Fax: +82-55-752-9339

E-mail: csassi@hanmail.net

Copyright@ 2019 by The Korean Society of Perinatology

This is an Open Access article distributed under the terms of the Creative Commons Attribution Non-Commercial License (http://creativecommons.org/ license/by-nc/4.0/), which permits unrestricted non-commercial use, distribution, and reproduction in any medium, provided that the original work is properly cited.
Objective: Levothyroxine sodium (LT4) is considered safe, and widely administered to premature infants with thyroid dysfunction. Late circulatory collapse (LCC) has not been defined clearly, but it has been characterized as refractory hypotension in premature infants. Recently, LCC after LT4 administration was reported in Japan. However, there is controversy on the aspect of LT4 as a risk factor of LCC. The purpose of this study was to investigate relations between LT4 administration and LCC in premature infants.

Methods: We retrospectively reviewed medical records of premature infants ( $\leq 32$ weeks gestation) admitted in Gyeongsang National University Hospital between 2011 and 2018. To investigate the relation between LT4 supplementation and LCC, clinical and laboratory findings were reviewed and compared between premature infants with and without LCC.

Results: Among 347 premature infants, LCC occurred in 21 (6.1\%) on median 19.0th day. Sixteen (76.2\%) of 21 infants with LCC were receiving LT4 and LCC was developed on median 3.0 days after LT4 initiation. Gestational age $\leq 28$ weeks, birth weight $<1.5 \mathrm{~kg}$, hemodynamically significant patent ductus arteriosus, culture proven sepsis, necrotizing enterocolitis, congenital hypothyroidism, use of LT4 and diuretics, values of serum thyroid stimulating hormone, free thyroxine and sodium were significantly statistically different between LCC and no LCC group. Prematurity $\leq 28$ weeks of gestation and LT4 replacement were risk factors of LCC on multivariate logistic regression analysis.

Conclusion: Supplementation of LT4 should be carefully considered in premature infants with thyroid dysfunction and serial monitoring of blood pressure should be warranted if LT4 was administered.

Key Words: Levothyroxine sodium, Circulatory collapse, Premature infant

\section{Introduction}

Thyroid hormones are important in central nervous system development. Congenital hypothyroidism (CH) defined as low thyroxine (T4) and elevated thyroid stimulating hormone (TSH), can cause cognitive deficit and growth abnormality. The newborn screening test (NST) has contributed to improve the outcome in infants with $\mathrm{CH}$, as levothyroxine sodium (LT4) administration has been initiated at an early stage. ${ }^{1}$ With the advent of NST, it is clear that thyroid dysfunction in preterm infants has been more prevalent than in term infants. ${ }^{1-4} \mathrm{~A}$ surge of TSH develops within hours of birth and then TSH declines steadily to below $5 \mathrm{mIU} / \mathrm{L}$ during the first postnatal week in infants with term gestation. However, TSH surge is weaker or absent at birth in premature infants because of immature hypothalamic-pituitary-thyroid axis. ${ }^{5}$ Patterns of thyroid dysfunction in premature infants could be classified as typical hypothyroidism or $\mathrm{CH}$ with delayed TSH elevation, transient hypothyroxemia of prematurity (THOP), and hyperthyrotropinemia, respectively. ${ }^{1,2,45}$ Although treatment of THOP or hyperthyrotropinemia in premature infants has been controversial to prevent poor cognitive outcome or neurodevelopment, LT4 has been considered safe and widely used in premature 
infants with thyroid dysfunction., ${ }^{1,5,6}$

Late circulatory collapse (LCC) in premature infants has not been defined clearly, but has been characterized as refractory hypotension occurring after the early neonatal period ( $>7$ days) in stable very low birth weight (BW) infants. ${ }^{7}$ Systemic hypotension is one of common problems in premature infants, which can be caused by hypovolemia, hemorrhage, myocardial dysfunction, sepsis, necrotizing enterocolitis (NEC), etc. So, apparent causes should be eliminated for diagnosis of LCC. Most LCC patients respond to glucocorticoid but do not respond to fluid and inotropes. So, relative adrenal insufficiency associated with prematurity has been suggested as pathophysiology of LCC. ${ }^{8}$ Recently, LCC has been reported in Korea and Japan, and LT4 supplementation before LCC was mentioned in the previous studies. ${ }^{9-12}$ However, LT4 supplementation as a risk factor of LCC has been controversial. Therefore, the purpose of this study was to investigate if LT4 administration to premature infants with thyroid dysfunction could affect development of LCC by comparing clinical and laboratory findings among premature infants.

\section{Methods}

Protocol of this study was reviewed and approved by the Insti- tutional Review Board of the Gyeongsang National Universtiy Hospital (GNUH 2019-04-006).

\section{Study population and clinical information}

Medical records of 401 premature infants born with $\leq 32$ weeks of gestation between January 2011 and March 2018 were retrospectively reviewed. Of them, premature infants who were admitted for at least 2 weeks in Gyeongsang National University Hospital were included ( $n=347$ ). Exclusions were decided as follows; premature infants with $\leq 32$ weeks of gestation who discharged in 2 weeks after birth including death (birth asphyxia, sepsis, or major congenital malformation) or transfer to other hospital (major congenital anomalies including congenital heart disease requiring open heart surgery) and premature infants who had acute refractory hypotension with apparent causes (Fig. 1). To investigate relation and relating factors between LT4 administration and LCC, incidences of LCC and LT4 administration were reviewed, and then clinical and laboratory findings including thyroid functions in patients with and without LCC were compared.

Clinical variables were collected from medical records regarding weeks of gestation, BW, sex, use of antenatal steroid, maternal thyroid disease, obstetric problems, multiple gestation, mode of delivery, Apgar score at 5-minute, type of feeding

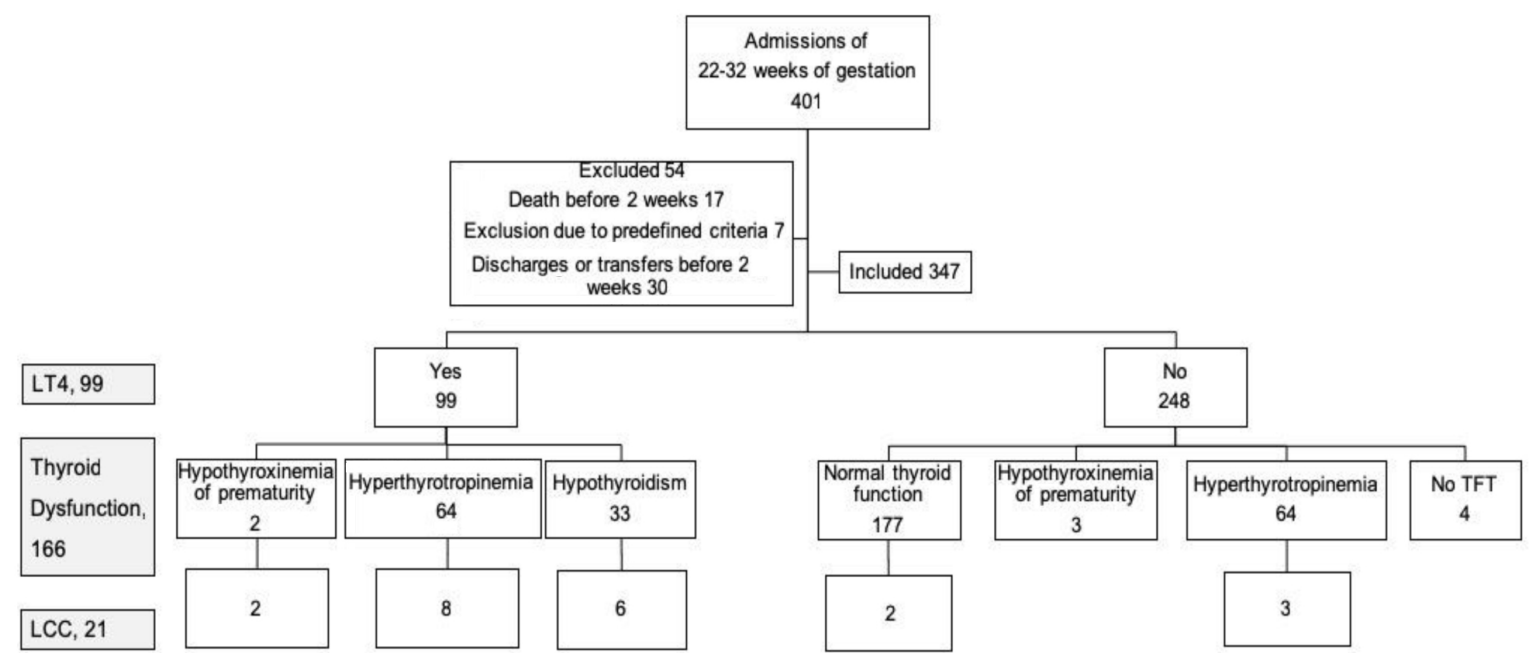

Fig. 1. Number of subjects in this study. Thyroid function was classified as normal (TSH $<5 \mathrm{mlU} / \mathrm{L}$ and fT $4<0.9 \mathrm{ng} / \mathrm{dL}$ ), hypothyroxinemia of prematurity (TSH $<5 \mathrm{mlU} / \mathrm{L}$ and fT $4<0.9 \mathrm{ng} / \mathrm{dL}$ ), hyperthyrotropinemia (TSH $\geq 5 \mathrm{mlU} / \mathrm{L}$ and fT4 $\geq 0.9 \mathrm{ng} / \mathrm{dL}$ ), and hypothyroidism (TSH $\geq 5 \mathrm{mlU} / \mathrm{L}$ and fT4 $<0.9 \mathrm{ng} / \mathrm{dL}$ ), respectively. Thyroid function was defined with the last values of serum TSH and fT4 during hospital stays or prior to LT4 administration. LT4 was initiated when serum TSH was $>20 \mathrm{mIU} / \mathrm{L}$, TSH was 5 to $20 \mathrm{mlU} / \mathrm{L}$ or rising, and/or fT4 was $<0.9 \mathrm{ng} / \mathrm{dL}$ on 2 or more consecutive tests with 1 or 2-week interval. LT4, levothyroxine sodium; LCC, late circulatory collapse; TFT, thyroid function test; TSH, thyroid stimulating hormone; $\mathrm{fT} 4$, free T4. 
formula. Use of antenatal steroid was defined as complete betamethasone injection to mother prenatally. Maternal thyroid disease was defined as hypothyroidism or hyperthyroidism of mother during pregnancy regardless of underlying cause. Among obstetric problems, prolonged premature rupture of membrane (PPROM) was defined as rupture of amniotic membrane over 18 hours before birth. Hypertensive condition included essential hypertension, pregnancy induced hypertension, or preeclampsia. Placenta problem contained bleeding from placenta previa or abruption. Premature labor pain was defined as labor pain and uterine contraction, which could not be controlled by tocolytics.

Prematurity-associated diseases were diagnosed as follows; respiratory distress syndrome was diagnosed as ground glass opacity on chest X-ray. Hemodynamically significant patent ductus arteriosus (hsPDA) was defined as ductal shunt from left to right and ratio of left atrium and aorta 1.4 on echocardiography. ${ }^{13} \mathrm{NEC}$ was diagnosed based on modified Bell's classification ${ }^{14}$ and intraventricular hemorrhage (IVH) was diagnosed as subependymal, intraventricular or intracerebral hemorrhage on brain ultrasonography. ${ }^{15}$ Sepsis was defined as use of antibiotics and positive result of culture with blood, urine, cerebrospinal fluid or others.

Clinical variables associated with short-term outcome were also investigated from medical records regarding bronchopulmonary dysplasia (BPD), retinopathy of prematurity (ROP), gross motor delay and mortality in 1 year, respectively. Premature infant who required supplemental oxygen or positive pressure ventilation at 36 weeks of gestation or postprandial 28 th day was defined as having a BPD. ${ }^{16}$ An ophthalmologic examination for detecting ROP was performed based on screening guideline in 3 or 4 weeks after birth and diagnosed as ROP with zone I-III, stage I - III, and plus. ${ }^{17}$ Gross motor delay was considered as premature infants who were undergoing rehabilitation therapy and mortality was investigated as infants who died in 1 year after birth in this study, respectively.

\section{Definition of LCC and treatment}

LCC was diagnosed retrospectively as follows. ${ }^{7}$ First, LCC occurs outside the transitional period. Second, a stable period exists before onset of LCC. Third, no apparent cause such as sepsis, massive bleeding, or NEC exists prior to onset of LCC. Fourth, hypotension and/or oliguria occur suddenly. Acute onset hypotension could be defined as systolic pressure reduced by $20 \%$ of previous value, and oliguria could be defined as urine output that abruptly decreased to less than $1 \mathrm{~mL} / \mathrm{kg} / \mathrm{hour}$ during a 4-hour interval. Fifth, hypotension and/or oliguria are resistant to intravascular volume expanders and inotropes. To be satisfied with the first and second definitions of LCC, premature infants who survived more than 2 weeks with stable period for at least 7 days were included in this study. Of inclusions, premature infants who had experienced LCC after postprandial 7th day were considered as LCC group. To dismiss apparent causes of acute hypotension in LCC group, we excluded patients with volume and inotropes resistant hypotension if they presented a hsPDA, hemodynamically significant congenital heart disease, any kind of surgery including ligation of PDA, NEC with modified Bell's stage 2 and more, ${ }^{14} \mathrm{IVH}$ with grade 3 and more, ${ }^{15}$ sepsis, acute blood loss, renal replacement therapy, or use of diuretics within 7 days from at the time of hypotension.

In Gyeongsang National University Hospital, blood pressure was serially monitored using noninvasive blood pressure measurement with oscillometric technique. When LCC was suspected, fluid challenge (intravenous normal saline of $10 \mathrm{mg} / \mathrm{kg} / \mathrm{dose}$, twice) and inotropes (continuous intravenous infusion of dopamine with or without dobutamine of $10-25 \mu \mathrm{g} / \mathrm{kg} /$ minute) were administered at first. And then intravenous injection of hydrocortisone ( $1 \mathrm{mg} / \mathrm{kg} /$ dose every 8 hour) was used if the fluid and inotropes were not effective. After recovery of blood pressure into previous range was accomplished, hydrocortisone was discontinued as soon as possible due to fear of incomplete exclusion of underlying causes such as sepsis or NEC at the time of hypotension and concern for aggravation of underlying causes by steroid.

\section{Criteria of thyroid dysfunction and LT4 administration}

Since thyroid dysfunction was relatively prevalent in premature infants with normal TSH or T4 on capillary NST, serum TSH and free T4 (fT4) were performed on postprandial 5-7th day together with NST. ${ }^{2,3}$ When serum TSH of 5 to $20 \mathrm{mIU} / \mathrm{L}$ or fT4 of $<0.9 \mathrm{ng} / \mathrm{mL}$ were reported on initial examination, serial TSH and fT4 were checked with a 1 or 2-week interval. In Gyeongsang National University Hospital, low fT4 was defined as a serum fT4 concentration of $\langle 0.9 \mathrm{ng} / \mathrm{dL}$, and elevated TSH as $>5 \mathrm{mIU} / \mathrm{L}$. Thyroid dysfunction was classified as hypothyroxinemia of 
prematurity, persistent hyperthyrotropinemia and hypothyroidism based on the last values of serum TSH and fT4 during hospital stays or before LT4 initiation. Hypothyroxinemia of prematurity was defined as low fT4 $(<0.9 \mathrm{ng} / \mathrm{dL})$ and normal TSH $(<5 \mathrm{mIU} / \mathrm{L})$, hyperthyrotropinemia as normal fT4 (0.9-2.2ng/dL) and elevated TSH ( $>5 \mathrm{mIU} / \mathrm{L})$, and hypothyroidism as low fT4 $(<0.9 \mathrm{ng} / \mathrm{dL})$ and elevated TSH $(>5 \mathrm{mIU} / \mathrm{L})$. CH was defined as a serum TSH $>20 \mathrm{mIU} / \mathrm{L}$ and fT4 $<0.9 \mathrm{ng} / \mathrm{dL} .{ }^{18} \mathrm{LT} 4(10-15 \mu \mathrm{g} / \mathrm{kg} / \mathrm{day})$ was initiated to patients with the following conditions; serum TSH of $>20 \mathrm{mIU} / \mathrm{L}$, serum TSH of 5 to $20 \mathrm{mIU} / \mathrm{L}$ and rising, or fT 4 of $0.9 \mathrm{ng} / \mathrm{dL}$ on 2 or more consecutive tests, respectively.

\section{Statistical analysis}

Data analyses were performed using SAS 9.4 (SAS Institute, Cary, NC, USA). A continuous variable was reported as median and interquartile range (IQR) or mean and standard deviation (SD) and a categorical variable was reported as number and percentage, respectively. Differences of continuous variables between two groups (LCC and no LCC) were compared using Wilcoxon rank-sum test because the variables did not satisfy the assumptions of normality and equal-variance based on results of Shapiro-Wilk test and Leven's F test. Differences of categorical variables between LCC and no LCC group were compared using Fisher's exact test. To evaluate risk for LCC among characteristic factors and LT4 supplementation, the authors performed univariate Firth's logistic regression for each factor because 21 events of LCC were relatively rare. And then we performed multivariate Firth's logistic regression to calculate the adjusted odds ratio (OR) of LT4. When multivariate analysis was performed, the statistically significant factors in univariate logistic regression analyses were included for adjustment. The authors also checked the multicollinearity between the factors for adjustment using correlation coefficient and excluded one of them when the coefficient was more than 0.7. Differences of short-term outcomes between the two groups and risk of LCC were evaluated as the same manner. Two-sided $P<0.05$ was set to determine the significance of variables in all analyses.

\section{Results}

In total, 347 premature infants were included in this study.
Exclusions were decided as premature infants who were discharged before 2 weeks after birth due to discharges with good condition, transfers to other hospitals, or death $(\mathrm{n}=47)$. Patients with acute refractory hypotension who did not fit predefined criteria of LCC were excluded acute refractory hypotension on day $4(n=1)$, and refractory hypotension with $\mathrm{NEC}(\mathrm{n}=3)$, culture proven sepsis $(\mathrm{n}=1), \mathrm{IVH} \geq$ stage $3(\mathrm{n}=1)$ and ligation of PDA $(n=1)$, respectively (Fig. 1). Among the 347 premature infants, mean gestational age (GA) was 30.4 \pm 2.1 (range: $23^{4}-32^{6}$ )

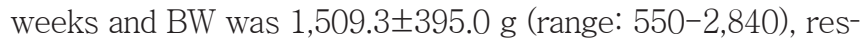
pectively. Males were 184 (53.0\%). Mean hospital stays were 48.2 \pm 30.1 days (range: 14-228). Rehabilitation in 1 year after birth was needed to $6.2 \%$, and mortality in 1 year was $3.3 \%$ of 347 premature infants.

\section{Incidences and clinical characteristics of LCC, thyroid dys- functions and use of LT4 in premature infants}

LCC occurred in 21 (6.1\%) of 347 premature infants on postprandial 19.0th day (IQR: 15-23.5, mean \pm SD: 19.5 \pm 5.9 ). All the patients with LCC received hydrocortisone of $1 \mathrm{mg} / \mathrm{kg} / \mathrm{dose}$ and treated for median 2.0 (IQR: 1.0-4.0, mean \pm SD: 2.5 \pm 1.7 ) days after LCC. Detailed characteristics of LCC patients were presented in a Supplementary Table 1.

Sixteen of 21 (76.2\%) patients with LCC received LT4 (Fig. 1 ), and experienced refractory hypotension in median 3 (IQR: 1.0-13.5, mean \pm SD: 5.9 \pm 6.6$)$ days after LT4 initiation. LCC occurred within 14 days after LT4 initiation in 13 (81.3\%) of 16

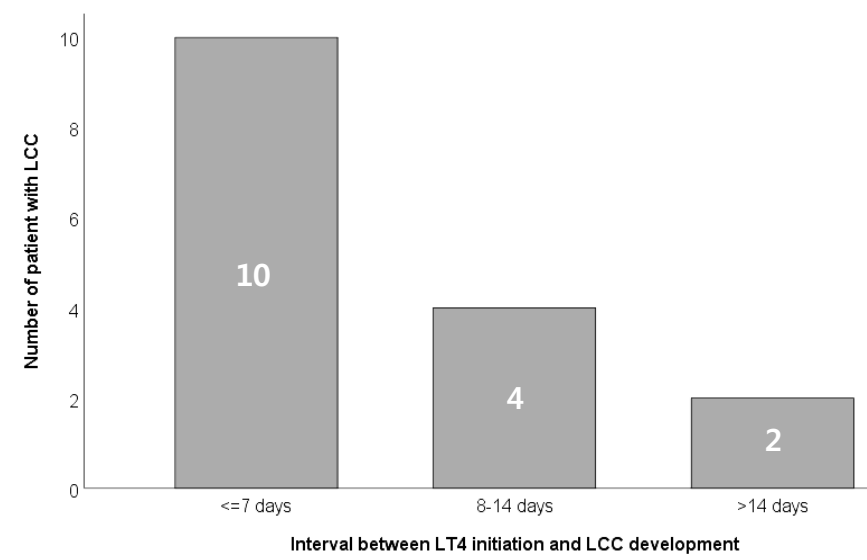

Fig. 2. Time interval (days) from initiation of LT4 and development of LCC, and number of patients with LCC in premature infants with $\leq 32$ weeks of gestation. LCC, late circulatory collapse; LT4, levothyroxine sodium. 
Table 1. Clinical and Laboratory Characteristics of Premature Infants with and without Late Circulatory Collapse

\begin{tabular}{|c|c|c|c|c|c|c|}
\hline & Total $(n=347)$ & $\operatorname{LCC}(n=21)$ & No LCC $(n=326)$ & $P$-value & OR $(95 \% \mathrm{Cl})$ & $P$-value* \\
\hline \multicolumn{7}{|l|}{ Demographic variables } \\
\hline Week of gestation & & & & $<0.0001^{\dagger}$ & & \\
\hline >28 (reference) & $281(80.98)$ & $8(38.10)$ & $273(83.74)$ & & 1.00 & \\
\hline Birth weight (g) & & & & $0.0002^{\neq}$ & & \\
\hline Sex & & & & $0.6965^{\ddagger}$ & & \\
\hline Male & $184(53.03)$ & $12(57.14)$ & $172(52.76)$ & & $1.178(0.492-2.823)$ & 0.7125 \\
\hline Female (reference) & $163(46.97)$ & $9(42.86)$ & 154 (47.24) & & 1.00 & \\
\hline Use of antenatal steroid & & & & $0.1082^{\ddagger}$ & & \\
\hline No (reference) & 332 (95.68) & $18(85.71)$ & 314 (96.32) & & 1.00 & \\
\hline Yes & $15(4.32)$ & $3(14.29)$ & $12(3.68)$ & & $4.76(1.283-17.663)$ & 0.0197 \\
\hline Obstetric problems & & & & $0.4453^{\dagger}$ & & \\
\hline PPROM & $128(36.89)$ & $121(37.12)$ & $7(33.33)$ & & $0.951(0.333-2.711)$ & 0.9245 \\
\hline Hypertensive condition & 35 (10.09) & $33(10.12)$ & $2(9.52)$ & & $1.149(0.257-5.148)$ & 0.8557 \\
\hline Placenta problem & $25(7.20)$ & $21(6.44)$ & $4(19.05)$ & & $3.223(0.901-11.526)$ & 0.0718 \\
\hline GDM & $21(6.05)$ & $20(6.13)$ & $1(4.76)$ & & $1.127(0.177-7.179)$ & 0.8994 \\
\hline Premature labor pain & $16(4.61)$ & $16(4.91)$ & $0(0.00)$ & & $0.467(0.023-9.311)$ & 0.6178 \\
\hline Outborn & $8(2.31)$ & $1(4.76)$ & $7(2.15)$ & & $3.117(0.46-21.1)$ & 0.244 \\
\hline Mode of delivery & & & & $0.5449^{\ddagger}$ & & \\
\hline VD & 137 (39.60) & $7(33.33)$ & $130(40.00)$ & & $0.775(0.311-1.929)$ & 0.5835 \\
\hline CS (reference) & $209(60.40)$ & $14(66.67)$ & $195(60.00)$ & & 1.00 & \\
\hline AS at 5-minute & $7(6-8)$ & $7(6-8)$ & $7(5-8)$ & $0.0343^{\S}$ & & \\
\hline Feeding formula & & & & $0.918^{\ddagger}$ & $0.767(0.630-0.933)$ & \\
\hline Breast milk & $243(70.43)$ & $15(71.43)$ & $228(70.37)$ & & $1.007(0.389-2.604)$ & 0.9883 \\
\hline WM/mixed (reference) & $102(29.57)$ & $6(28.57)$ & $96(29.63)$ & & 1.00 & \\
\hline \multicolumn{7}{|c|}{ Prematurity-related diseases and medications } \\
\hline Surfactant for RDS & & & & $0.7385^{\dagger}$ & $0.769(0.232-2.551)$ & 0.6672 \\
\hline No (reference) & $44(12.68)$ & $3(14.29)$ & $41(12.58)$ & & 1.00 & \\
\hline Yes & $303(87.32)$ & $18(85.71)$ & $285(87.42)$ & & & \\
\hline
\end{tabular}


Table 1. Continued

\begin{tabular}{|c|c|c|c|c|c|c|}
\hline & Total $(n=347)$ & $\operatorname{LCC}(n=21)$ & No LCC $(n=326)$ & $P$-value & $\mathrm{OR}(95 \% \mathrm{Cl})$ & $P$-value* \\
\hline Ibuprofen for hsPDA & & & & $0.0002^{\dagger}$ & $9.15(3.3-25.373)$ & $<0.0001$ \\
\hline No (reference) & 323 (93.08) & $14(66.67)$ & $309(94.79)$ & & 1.00 & \\
\hline Yes & $24(6.92)$ & $7(33.33)$ & $17(5.21)$ & & & \\
\hline IVH ( $\geq$ grade 3 ) & & & & $0.075^{\dagger}$ & $4.078(1.123-14.809)$ & 0.0327 \\
\hline No (reference) & $330(95.10)$ & $18(85.71)$ & $312(95.71)$ & & 1.00 & \\
\hline Yes & $17(4.90)$ & $3(14.29)$ & $14(4.29)$ & & & \\
\hline Sepsis, culture proven & & & & $0.0041^{\dagger}$ & $3.864(1.595-9.362)$ & 0.0028 \\
\hline No (reference) & $275(79.25)$ & $11(52.38)$ & $264(80.98)$ & & 1.00 & \\
\hline Yes & $72(20.75)$ & $10(47.62)$ & $62(19.02)$ & & & \\
\hline NEC ( $\geq$ stage 2 ) & & & & $0.0025^{\dagger}$ & $7.742(2.494-24.036)$ & 0.0004 \\
\hline No (reference) & 329 (94.81) & $16(76.19)$ & $313(96.01)$ & & 1.00 & \\
\hline Yes & $18(5.19)$ & $5(23.81)$ & $13(3.99)$ & & & \\
\hline Congenitial hypothyroidisim & & & & $0.0493^{\dagger}$ & 3.795 (1.204-11.957) & 0.0228 \\
\hline No (reference) & $319(93.00)$ & $17(80.95)$ & 302 (93.79) & & 1.00 & \\
\hline Yes & $24(7.00)$ & $4(19.05)$ & $20(6.21)$ & & & \\
\hline Use of LT4 & & & & $<0.0001^{\ddagger}$ & $8.748(3.22-23.766)$ & $<0.0001$ \\
\hline No (reference) & $248(71.47)$ & $5(23.81)$ & $243(74.54)$ & & 1.00 & \\
\hline Yes & $99(28.53)$ & $16(76.19)$ & $83(25.46)$ & & & \\
\hline Use of diuretics & & & & $0.0017^{\dagger}$ & $4.466(1.835-10.871)$ & 0.001 \\
\hline No (reference) & $282(81.27)$ & $11(52.38)$ & $271(83.13)$ & & 1.00 & \\
\hline Yes & 65 (18.73) & $10(47.62)$ & $55(16.87)$ & & & \\
\hline Use of caffeine & & & & $0.008^{\ddagger}$ & $14.746(0.869-250.278)$ & 0.0625 \\
\hline No (reference) & $83(23.92)$ & $0(0.00)$ & $83(25.46)$ & & 1.00 & \\
\hline Yes & $264(76.08)$ & $21(100.0)$ & $243(74.54)$ & & & \\
\hline Dopa/dobuta in 7 days & & & & $0.1208^{\neq}$ & $2(0.837-4.781)$ & 0.1191 \\
\hline No (reference) & $235(67.72)$ & $11(52.38)$ & $224(68.71)$ & & 1.00 & \\
\hline Yes & $112(32.28)$ & $10(47.62)$ & $102(31.29)$ & & & \\
\hline \multicolumn{7}{|l|}{ Laboratory findings } \\
\hline Serum cortisol ( $\mu \mathrm{g} / \mathrm{dL})$ & $4.35(16,1.90-8.65)$ & $3.57(6,2.04-6.08)$ & $5.80(10,1.85-14.71)$ & $0.495^{5}$ & $0.914(0.744-1.121)$ & 0.388 \\
\hline TSH (mIU/L) & $5.58(343,3.59-14.78)$ & $15.91(21,6.55-38.25)$ & $5.36(322,3.54-14.12)$ & $0.003^{5}$ & $1.019(1.01-1.03)$ & 0.006 \\
\hline fT4 (ng/dL) & $1.37(335,1.10-1.61)$ & $0.97(21,0.97-1.25)$ & $1.40(314,1.13-1.61)$ & $<0.001^{\S}$ & $11.236(3.497-35.714)$ & $<0.001$ \\
\hline Serum sodium $(m E q / L)^{\|}$ & $130.7(145,127.7-132.1)$ & $125.9(18,124.7-127.0)$ & $131.0(127,129.3-132.4)$ & $<0.001^{5}$ & $1.326(1.153-1.522)$ & $<0.001$ \\
\hline
\end{tabular}

Values are presented as number (\%) or median (IQR), or median (n, IQR).

Abbreviations: LCC, late circulatory collapse; OR, odds ratio; Cl, confidence interval; PPROM, prolonged premature rupture of membrane with more than 18 hours; hypertensive condition included essential hypertension, pregnancy induced hypertension, or preeclampsia; GDM, gestational diabetes mellitus; VD, vaginal delivery; CS, cesarean section; AS, Apgar score; RDS, respiratory distress syndrome; hsPDA, hemodynamically significant patent ductus arteriosus; IVH, intraventricular hemorrhage; NEC, necrotizing enterocolitis; LT4, levothyroxine sodium; TSH, thyroid stimulating hormone; fT4, free T4; IQR, interquartile range.

* P-value was derived from logistic regression model with Firth's peneralized likelihood.

${ }^{\dagger} P$-value was derived from Fisher's exact test, respectively.

${ }^{\ddagger} P$-value was derived from Chi-square test, respectively.

${ }^{\S} P$-value was derived from Wilcoxon rank-sum test, respectively.

"The lowest serum sodium during hospital stays in each premature infant was analyzed. 
patients (Fig. 2). LCC preceded LT4 administration, in one of the patients (No. 9 on Supplementary Table 1).

To investigate whether LT4 administration could be a risk factor of LCC or not, clinical characteristics including use of LT4 were compared between LCC and no LCC group (Table 1). Weeks of gestation (27.8 \pm 2.5 vs. $30.6 \pm 2.0, P<0.001)$, BW $(1,066.7 \pm 326.3$ g vs. $1,537.9 \pm 382.2$ g, $P<0.001)$, and Apgar score at 5 -minutes ( $6.1 \pm 2.4$ vs. $7.2 \pm 1.7, P=0.034$ ) were less in LCC than in no LCC group, respectively. Ratio of gender, use of antenatal steroid, maternal thyroid disease, obstetric problems, multiple gestation, ratio of outborn, mode of delivery, or breast milk was not significantly different between the two groups. Use of Ibuprofen for hsPDA, sepsis, NEC ( $\geq$ stage 2), and congenital hypothyroidism were more prevalent in patients with LCC than in patients without LCC, respectively. LT4, caffeine and diuretics during hospital stays were more often administered in patients with LCC than in patients without LCC, respectively.

Median value of serum cortisol was $4.35 \mathrm{\mu g} / \mathrm{dL}$ (IQR: 1.908.65, mean \pm SD: $4.34 \pm 3.27)$ in total $(n=16)$ and there was no statistical difference between the two groups ( $P=0.495)$. Median value of TSH was higher in LCC than in no LCC group (15.91 vs. $5.36 \mathrm{mIU} / \mathrm{L}, P=0.003)$ and $\mathrm{fT} 4$ was lower in LCC than in no LCC group ( $0.97 \mathrm{vs} .1 .40 \mathrm{ng} / \mathrm{dL}, P<0.001$ ). The lowest serum sodium level during hospital stays in each patient was investigated and patients with LCC presented lower serum sodium than patients without LCC (median 125.9 vs. $131.0 \mathrm{mEq} / \mathrm{L}, P<0.001$, Table 1)

Three-hundred forty-three infants underwent serum thyroid function test (serum TSH and fT4) simultaneously with capillary NST (Guthrie or tandem mass spectrometry) on postprandial day 5-7 (Fig. 1). If serum TSH was $5-20 \mathrm{mIU} / \mathrm{L}$ or fT 4 was $<0.9 \mathrm{ng} / \mathrm{dL}$ on initial examination, serial tests were performed with 1 or 2 -week interval. The last values of TSH and fT4 during hospital stays or immediately prior to LT4 administration were included in this study, which were reported on median 18.0 (IQR: 12.0-28.0, mean \pm SD: $21.5 \pm 14.0)$ after birth. Thyroid dysfunction was presented in 166 (47.8\%) premature infants during hospital stays, and 99 (28.5\%) patients were prescribed LT4 on median 17.0 (IQR: 13.0-22.0, mean \pm SD: $20.5 \pm 15.0)$ days after birth. Thyroid dysfunctions were diagnosed as hypothyroxinemia (TSH $<5 \mathrm{mIU} / \mathrm{L}$ and fT4 $<0.9 \mathrm{ng} / \mathrm{dL}$ ) in 5 , persisted hyperthyrotropinemia (TSH $>5 \mathrm{mIU} / \mathrm{L}$ and normal fT4) in 128, and hypothyroidism (persisted elevation of TSH $>5 \mathrm{mIU} / \mathrm{L}$ and $\mathrm{fT} 4<0.9 \mathrm{ng} / \mathrm{dL}$ ) in 33 patients, respectively (Fig. 1). Among 33 pateints with hypothyroidism, 24 patients with congential hypothyroidism (TSH $>20 \mathrm{mIU} / \mathrm{L}$ and fT4 $<0.9 \mathrm{ng} / \mathrm{dL}$ ) were included. LCC developed in 19 of 166 (11.4\%) patients with thyroid dysfunctions, and 2 of 177 (1.1\%) infants with normal thyroid function (Fig. 1 and Supplementary Table 1). LT4 was more frequently prescribed in LCC than in no LCC group (76.2\% vs. $25.5 \%, P<0.001)$.

\section{Risk factors of LCC}

To investigate risk factor of LCC, variables with statistically significant differences between the groups (Table 1) were analyzed using multivariable logistic regression model with Firth's peneralized likelihood (Table 2). GA $\leq 28$ weeks (OR 3.51, $P=0.041$, 95\% confidence interval [CI] 1.05-11.75) and LT4 administration (OR 9.18, $P<0.001$, 95\% CI 2.81-30.01) were risk factors of LCC. BW was not included in analysis for risk factor of LCC because it showed high correlation with GA ( $r=0.795$, $P<0.001)$. Use of diuretics was statistically significant variable

Table 2. OR of Risk Factors for Late Circulatory Collapse in Premature Infants

\begin{tabular}{|c|c|c|}
\hline & $\mathrm{OR}(95 \% \mathrm{Cl})$ & $P$-value \\
\hline \multicolumn{3}{|l|}{ Week of gestation } \\
\hline$\leq 28$ & $3.512(1.050-11.749)$ & 0.0415 \\
\hline$>28$ (reference) & 1.00 & \\
\hline \multicolumn{3}{|l|}{ Ibuprofen for hsPDA } \\
\hline No (reference) & 1.00 & \\
\hline Yes & $3.258(0.883-12.016)$ & 0.0762 \\
\hline \multicolumn{3}{|l|}{ Sepsis, culture proven } \\
\hline No (reference) & 1.00 & \\
\hline Yes & $2.488(0.854-7.250)$ & 0.0948 \\
\hline \multicolumn{3}{|l|}{ NEC $\geq$ stage 2} \\
\hline No (reference) & 1.00 & \\
\hline Yes & $2.493(0.591-10.516)$ & 0.2136 \\
\hline \multicolumn{3}{|l|}{ Use of LT4 } \\
\hline No (reference) & 1.00 & \\
\hline Use of LT4 (without congenital hypothyroidism)* & $9.184(2.811-30.009)$ & 0.0002 \\
\hline Use of LT4 (with congenital hypothyroidism) & $6.168(1.335-28.506)$ & 0.0198 \\
\hline \multicolumn{3}{|c|}{$\begin{array}{l}\text { P-value was derived from logistic regression model with Firth's peneralized likeli- } \\
\text { hood. } \\
\text { Abbreviations: OR, odds ratio; Cl, confidence interval; hsPDA, hemodynamically } \\
\text { significant patent ductus arteriosus; NEC ( } \geq \text { stage 2), necrotizing enterocolitis with } \\
\text { modified Bell's class stage } 2 \text { and more; LT4, levothyroxine sodium. } \\
\text { *Use of LT4 (without congenital hypothyroidism) means LT4 supplementation } \\
\text { in cases with thyroid dysfunction except congenital hypothyroidism, such as } \\
\text { persistent hypothyroxinemia or hyperthyrotropinemia. }\end{array}$} \\
\hline
\end{tabular}


between the two groups ( $P=0.002)$ and had high OR for LCC on univariate analysis (OR 4.47, $P=0.001,95 \%$ CI 1.84-10.87) (Table 1). However, use of diuretics was not included as a risk factor of LCC on multivariate regression analysis because uses of diuretics within 7 days of LCC were already excluded as an apparent cause of acute hypotension in this study. fT4 was also one of statistically significant variables between LCC and no LCC group $(P<0.001)$ and it showed high OR for LCC on univariate analysis (OR 11.236 per $1 \mathrm{ng} / \mathrm{dL}$ decrease, $P<0.001$, 95\% Cl 3.497-35.714) (Table 1). However, when fT4 was analyzed adjusted with GA and LT4 using multivariate regression analysis, there was no statistical significance as a risk factor for LCC (OR 2.320, $P=0.233$, 95\% CI 0.582-9.259).

\section{Short-term outcomes and risk of LCC}

On the aspect of short-term outcome of LCC, BPD (81.0\% vs. $17.2 \%, P<0.001)$ and ROP (31.6\% vs. $11.3 \%, P=0.002)$ were more prevalent in premature infants with LCC than in premature infants without LCC, respectively. Number of infants with hospital stays $\geq 50$ days were higher in LCC than in no LCC group ( $71.4 \%$ vs. $29.5 \%, P<0.001)$. Gross motor delay adjusted with corrected age in 1 year (9.5\% vs. 6.0\%, $P=0.631)$ was not different between the two groups, but mortality in 1 year after birth (19.1\% vs. $2.2 \%$, $P=0.003$ ) was higher in LCC than no LCC group. LCC could influence development of BPD (OR 12.0, P<0.001, 95\% CI 3.0-47.6) when multivariate logistic regression model was performed with adjusted GA (Table 3 ).

\section{Discussion}

Incidence of LCC in Gyeongsang National University Hospital was $6.1 \%$ in total and more prevalent in patients with LT4 $(16.2 \%$, 16/99) than in patients without LT4 administration (2.0\%, 5/248, $P<0.001$ ) (Fig. 1). LCC was also more frequently developed in premature infants with $\leq 28$ than in infants with $28-32$ weeks of gestation $(P<0.001$, Table 1$)$. According to previous studies, the incidence of LCC has been reported between 4 and $43 \%$.,11,12,19 In one Korean facility, LCC was diagnosed in $6.7 \%$ of premature infants with $<33$ weeks of gestation and in Japan, $11.6 \%$ of very low BW infants experienced LCC, respectively, ${ }^{9,11}$

Prematurity with $<26$ weeks of gestation, LT4, amidotrizoic acid, antenatal steroid and fentanyl were reported as risk factors for LCC. ${ }^{711,12,19}$ In this study, LT4 and prematurity less than and 28 weeks of gestation were the risk factors of LCC (Table 2). As a risk factor of LCC, LT4 administration in premature infants has been still inconsistent according to reported studies. ${ }^{2,7,910-12,20}$ Kawai et al. ${ }^{11}$ and Okada et al. ${ }^{20}$ reported LT4 administration could develop LCC in premature infants, respectively. Shimokaze et al. ${ }^{12}$ insisted practice changes such as use of antenatal steroid and fentanyl could have more impact on development of LCC than use of LT4.

Many confounding factors that could affect systemic circulation in premature infants, different neonatal care strategies per facility, various inclusion of each study and the unestablished definition of LCC could attribute to the various incidences of LCC and the inconsistent results for LT4 as a risk factor of LCC., ${ }^{9,12} \mathrm{In}$

Table 3. Short-term Outcomes and Influences of Late Onset Circulatory Collapse in Premature Infants

\begin{tabular}{|c|c|c|c|c|c|c|}
\hline & Total $(n=347)$ & $\operatorname{LCC}(n=21)$ & No LCC (n=326) & $P$-value & Adjusted OR (95\% Cl) & $P$-value* \\
\hline \multicolumn{7}{|l|}{ Outcome variables } \\
\hline BPD & $73(21.10)$ & $17(80.95)$ & $56(17.23)$ & $<0.0001^{\dagger}$ & $13.919(3.883,49.895)$ & $<0.0001$ \\
\hline ROP & $42(12.43)$ & $6(31.58)$ & $36(11.29)$ & $0.0202^{\dagger}$ & $1.045(0.326,3.343)$ & 0.94 \\
\hline Hospital stays $\leq 50$ days & $111(31.99)$ & 15 (71.43) & $96(29.45)$ & $<0.0001^{\ddagger}$ & $0.411(0.124,1.355)$ & 0.1441 \\
\hline Gross motor delay $^{5}$ & $21(6.23)$ & $2(9.52)$ & $19(6.01)$ & $0.6305^{\dagger}$ & $1.477(0.322,6.77)$ & 0.6153 \\
\hline Mortality" & $11(3.29)$ & $4(19.05)$ & $7(2.24)$ & $0.0029^{\dagger}$ & $3.45(0.83,14.335)$ & 0.0884 \\
\hline
\end{tabular}

Values are presented as number (\%).

Abbreviations: LCC, late circulatory collapse; $\mathrm{OR}$, odds ratio; Cl, confidence interval; BPD, bronchopulmonary dysplasia; ROP, retinopathy of prematurity.

* $P$-value was derived from logistic regression model adjusted to gestational age with Firth's peneralized likelihood (event="LCC").

${ }^{\dagger} P$-value was derived from Fisher's exact test, respectively.

${ }^{\ddagger} \mathrm{P}$-value was derived from and Chi-square test, respectively.

${ }^{5}$ Gross motor delay was investigated as premature infants undergoing rehabilitation therapy in 1 year with adjusted gestational age.

"Moratlity was investigated as premature infants who were died in 1 year after birth. 
this study, the definition of LCC and inclusion were very strictly decided. To exclude apparent cause that affect systemic circulation, the authors excluded subjects with early death in 2 weeks after birth, or unstable clinical courses before and after 1 week of LCC development. The exclusions might contribute a small number of inclusions and LCC in this study.

Thyroid dysfunctions during hospitalization were presented in $47.8 \%$ of premature infants with $\leq 32$ weeks of gestation, and LT4 administered to $28.5 \%$ of them. Incidences of thyroid dysfunction and LT4 administration in premature infants have been reported as $9.1-53.3 \%$ and $8-59 \%$, respectively. $3,4,9,11,12,19$ Compared with other studies, incidences of thyroid dysfunction and LT4 administration were relatively prevalent in this study. Exposure to povidone iodine, dopamine or dobutamine, and amidotrizoate may affect thyroid function, and thus potentiate prescription of LT4. ${ }^{19,21}$ In Gyeongsang National University Hospital, umbilical venous catheter or peripherally inserted central venous catheter was often inserted to neonates born prematurely with $\leq 32$ weeks of gestation with skin preparation using $10 \%$ povidone iodine. Dopamine with or without dobutamine was often started with $2.5-5 \mu \mathrm{g} / \mathrm{kg} / \mathrm{min}$ to maintain mean blood pressure of appropriate for GA and subsequent urine output in 7 days after birth (Table 1). In addition, relatively early venous thyroid function test on the postprandial 5th to 7th day might be one of the reasons for relatively high incidence of thyroid dysfunction in Gyeongsang National University Hospital. And thyroid dysfunctions were strictly defined as low fT4 of $<0.9$, compared with fT4 of $<0.7$ or $0.8 \mathrm{ng} / \mathrm{dL}$ on previous reports. ${ }^{2,3}$ Those factors could affect relatively frequent occurrence of thyroid dysfunction in Gyeongsang National University Hospital. And LT4 administration has been relatively liberally dispensed in Gyeongsang National University Hospital because thyroid dysfunction in premature infants may induce poor developmental outcome and LT4 administration was considered safe in premature infants.

Maternal thyroid dysfunction can affect fetal or neonatal thyroid function ${ }^{18}$ and the authors investigated maternal thyroid disease unlike other studies. Maternal thyroid dysfunction contained Graves disease, Hashimoto's thyroiditis, or any other possible cause of hyper or hypothyroidism in this study. A total of 15 mothers had thyroid disease, and 13 babies born from the mothers presented thyroid dysfunction during hospital stays.
Eight of 13 babies received LT4 but maternal thyroid disease was not statistically significantly different between LCC and no LCC group ( $P=0.0543$, Table 1$)$.

A wide range of serum cortisol (0.85-9.94 $\mu \mathrm{g} / \mathrm{dL})$ and diverse thyroid functions were reported in patients with LCC (Supplementary Table 1). Relative adrenal insufficiency has been considered as an underlying pathophysiology of LCC in premature infants. ${ }^{7,12}$ Thyroid hormone replacement is well known to increase cortisol metabolism and clearance. LT4 administration to premature infants may have risk of inducing relative adrenal insufficiency. ${ }^{7,9}$ Although serum cortisol was examined in only six patients with LCC before use of hydrocortisone, a wide range of serum cortisol and temporal relation with LT4 initiation (except No. 9 case Supplementary Table 1) might support a relative adrenal insufficiency as a underlying pathophysiology of LCC, indirectly.

In this study, serum fT4 and sodium were lower in LCC than in no LCC group, respectively (Table 1). Although lower fT4 did not have statistically significant OR for LCC on multivariate regression analysis in this study and hyponatremia is frequently presented in premature infants, ${ }^{22-24}$ LCC occurrence should be monitored when LT4 was administered to premature infants with hyponatremia and low fT4 after the transitional period.

When risk factors of LCC were analyzed, congenital hypothyroidism and LT4 administration were included together because they did not show high collinearity and correlation $(\mathrm{r}=0.431$, $P<0.001)$ and it was necessary to confirm which factors had more influence on development of LCC. Based on the result, LT4 administration was one of risk factors of LCC rather than congenital hypothyroidism (Table 2).

Persistent hypothyroxinemia was diagnosed in five patients in this study. Of them, LT4 administered to 2 infants and both experienced LCC. Since LCC occurred after LT4 initiation even though in small number of patients with hypothyroxinemia, LCC could affect development of BPD (Table 3) and LT4 replacement in patient with transient hypothyroxinemia of prematurity has not been established on the aspect of long-term neurologic outcome, LT4 administration might be considered carefully in premature infants with hypothyroxinemia without TSH elevation. Further study with large numbers of hypothyroxinemia of prematurity would be warranted.

Our study has limitations. First, this was a retrospective case- 
control study in one center only. Second, a small number of LCC patients and extremely premature infants were included. Third, LCC preceded LT4 administration in one of the patients (No. 9 on Supplementary Table 1) in this study. However, this study has several meanings and strengths despite such limitations. First, LCC was strictly defined. Case of refractory hypotension with apparent cause could lead to circulatory collapse within 7 days before and after the onset of hypotension, were excluded. Second, LT4 administration had relatively higher OR on development of LCC adjusted with GA in strictly selected stable premature infants without apparent cause. Third, we reviewed laboratory tests including TSH and fT4, and investigated the correlation or difference between premature infants with LCC and without LCC.

The major purpose of LT4 administration is to prevent poor developmental outcome. However, since there has been a lack of consensus in treating thyroid dysfunction of premature infants especially in case of hypothyroxinemia of prematurity and hyperthyrotropinemia, deciding on LT4 administration has been remained a paradox. ${ }^{1,5}$ A large-scale controlled study and consensus on LT4 administration in premature infants with thyroid dysfunctions would be necessary. Based on results of this study, LT4 administration to premature infants with persistent hypothyroxinemia or hyperthyrotropinemia might be considered cautiously. And careful monitoring of blood pressure should be performed when LT4 was initiated.

\section{Acknowledgements}

The statistical analyses in this study were supported by medical research statistics of Gyeongsang National University Hospital.

\section{References}

1) lijima S. Current knowledge of transient hypothyroxinemia of prematurity: to treat or not to treat? J Matern Fetal Neonatal Med 2019;32: 2591-7.

2) Kaluarachchi DC, Colaizy TT, Pesce LM, Tansey M, Klein JM. Congenital hypothyroidism with delayed thyroid-stimulating hormone elevation in premature infants born at less than 30 weeks gestation. J Perinatol 2017;37:277-82

3) Lee JH, Kim SW, Jeon GW, Sin JB. Thyroid dysfunction in very low birth weight preterm infants. Korean J Pediatr 2015;58:224-9.

4) Chung HR, Shin $\mathrm{CH}$, Yang SW, Choi CW, Kim BI, Kim EK, et al. High incidence of thyroid dysfunction in preterm infants. J Korean Med Sci 2009; 24:627-31

5) La Gamma EF, Korzeniewski SJ, Nigel Paneth PB. Transient hypothyroxinemia of prematurity. Neoreviews 2016;17:e394-402.

6) Chung ML, Yoo HW, Kim KS, Lee BS, Pi SY, Lim G, et al. Thyroid dysfunctions of prematurity and their impacts on neurodevelopmental outcome. J Pediatr Endocrinol Metab 2013;26:449-55.

7) Kawai M. Late-onset circulatory collapse of prematurity. Pediatr Int 2017:59:391-6.

8) Masumoto K, Kusuda S, Aoyagi H, Tamura Y, Obonai T, Yamasaki C, et al Comparison of serum cortisol concentrations in preterm infants with or without late-onset circulatory collapse due to adrenal insufficiency of prematurity. Pediatr Res 2008;63:686-90

9) Lee WJ, Kim MY, Cho HJ, Lee JS, Son DW. Clinical features of late-onset circulatory collapse in preterm infants. Korean J Perinatol 2013;24:14857.

10) Takizawa F, Kashimada K, Enomoto K, Miyai K, Ono M, Asada G, et al. Two preterm infants with late onset circulatory collapse induced by levothyroxine sodium. Pediatr Int 2010;52:e154-7.

11) Kawai M, Kusuda S, Cho K, Horikawa R, Takizawa F, Ono M, et al. Nationwide surveillance of circulatory collapse associated with levothyroxine administration in very-low-birthweight infants in Japan. Pediatr Int 2012;54:177-81

12) Shimokaze T, Saito E, Akaba K. Increased incidence of late-onset circulatory collapse after changing clinical practice: a retrospective investigation of causative factors. Am J Perinatol 2015;32:1169-76.

13) Sehgal A, McNamara PJ. Does echocardiography facilitate determination of hemodynamic significance attributable to the ductus arteriosus? Eur J Pediatr 2009;168:907-14

14) Bell MJ, Ternberg JL, Feigin RD, Keating JP, Marshall R, Barton L, et al. Neonatal necrotizing enterocolitis. Therapeutic decisions based upon clinical staging. Ann Surg 1978;187:1-7.

15) Papile LA, Burstein J, Burstein R, Koffler H. Incidence and evolution of subependymal and intraventricular hemorrhage: a study of infants with birth weights less than 1,500 gm. J Pediatr 1978;92:529-34.

16) Jobe AH, Bancalari E. Bronchopulmonary dysplasia. Am J Respir Crit Care Med 2001;163:1723-9.

17) Fierson WM, American Academy of Pediatrics Section on Ophthalmology American Academy of Ophthalmology, American Association for Pediatric Ophthalmology and Strabismus, American Association of Certified Orthoptists. Screening examination of premature infants for retinopathy of prematurity. Pediatrics 2013;131:189-95.

18) LaFranchi SH. Thyroid hormone studies. In: Kliegman RM, Stanton BF, Geme JS, Schor NF, editors. Nelson textbook of pediatrics. 20th ed. Philadelphia: Elsevier; 2016. p.2664

19) Ares S, Quero J, de Escobar GM. lodine balance, iatrogenic excess, and thyroid dysfunction in premature newborns. Semin Perinatol 2008;32: 407-12.

20) Okada J, Iwata S, Hirose A, Kanda H, Yoshino M, Maeno Y, et al. Levothyr- 
oxine replacement therapy and refractory hypotension out of transitional period in preterm infants. Clin Endocrinol (Oxf) 2011;74:354-64.

21) Haugen BR. Drugs that suppress TSH or cause central hypothyroidism. Best Pract Res Clin Endocrinol Metab 2009;23:793-800.

22) Kloiber LL, Winn NJ, Shaffer SG, Hassanein RS. Late hyponatremia in very-low-birth-weight infants: incidence and associated risk factors. J Am Diet Assoc 1996;96:880-4.
23) Kim YJ, Lee JA, Oh S, Choi CW, Kim EK, Kim HS, et al. Risk factors for lateonset hyponatremia and its influence on neonatal outcomes in preterm infants. J Korean Med Sci 2015;30:456-62.

24) Gokçe IK, Oguz SS. Late onset hyponatremia in preterm newborns: is the sodium content of human milk fortifier insufficient? J Matern Fetal Neonatal Med 2018 Sep 20 [Epub]. https://doi.org/10.1080/14767058.2 018.1517314. 
Supplementary Table 1. Clinical and Laboratory Findings of Patients with Late Circulatory Collapse

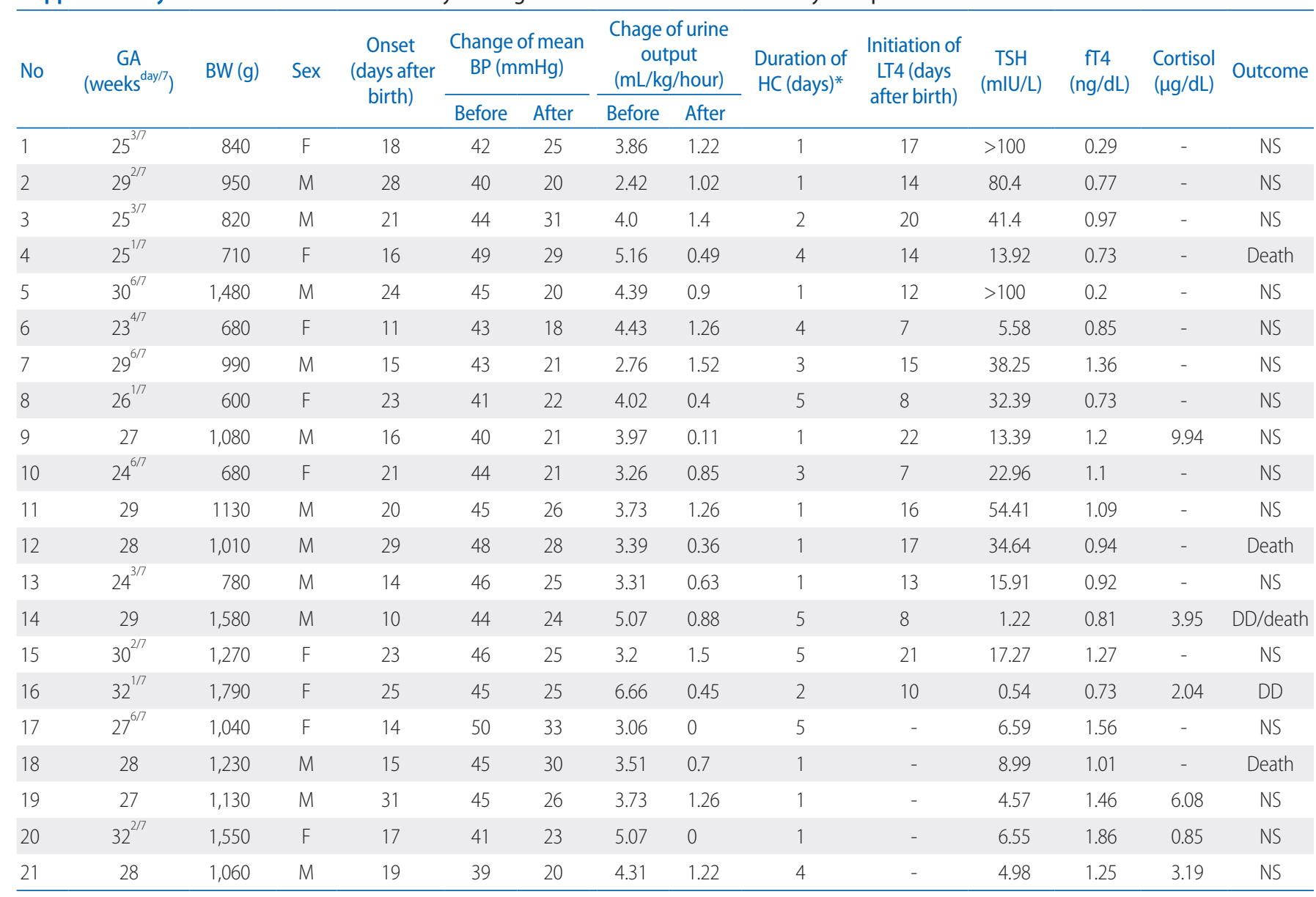

Abbreviations: GA, gestational age; BW, birth weight; BP, blood pressure; HC, hydrocortisone; LT4, leveothyroxine sodium; TSH, thyroid stimulating hormone; fT4, free T4; F, female; M, male; NS, no specific; DD, gross motor developmental delay.

*Duration of HC (days) means treatment duration of hydrocortisone with $1 \mathrm{mg} / \mathrm{kg} /$ dose at least every 8 hour. 